\title{
Improving Transient Response of Power Converter in a Stand-Alone Microgrid Using Virtual Synchronous Generator
}

\author{
Cao-Khang Nguyen ${ }^{1}$, Thai-Thanh Nguyen ${ }^{1}{ }^{\mathbb{D}}$, Hyeong-Jun Yoo ${ }^{1}$ and Hak-Man Kim ${ }^{1,2, *}$ \\ 1 Department of Electrical Engineering, Incheon National University, Songdo-dong, 119 Academy-ro, \\ Yeonsu-gu, Incheon 22012, Korea; caokhangnguyen@inu.ac.kr (C.-K.N.); ntthanh@inu.ac.kr (T.-T.N.); \\ yoohj@inu.ac.kr (H.-J.Y.) \\ 2 Research Institute for Northeast Asian Super Grid, Incheon National University, 119 Academy-ro, \\ Yeonsu-gu, Incheon 22012, Korea \\ * Correspondence: hmkim@inu.ac.kr; Tel.: +82-32-835-8769; Fax: +82-32-835-0773
}

Received: 31 October 2017; Accepted: 21 December 2017; Published: 23 December 2017

\begin{abstract}
Multiple power converters based on the droop controllers have been used widely in the microgrid (MG) system. However, owing to the different response time among several types of power converters such as grid-feeding and grid-forming converters, low frequency oscillation occurs with high overshoot in the transient state. This paper proposes a novel control strategy based on the virtual synchronous generator (VSG) for improving transient response of parallel power converters during large disturbance in the stand-alone microgrid. The proposed VSG control, which inherits the transient state characteristic of the synchronous generator, can provide inertia virtually to the system. The transient response of voltage and frequency is improved, while the total system inertia response is compensated. Thus, the system stability can be enhanced by using the proposed VSG control. Additionally, the small signal analysis of the conventional VSG controller and the proposed VSG controller are carried out to show the effectiveness of the proposed VSG controller. The derivation of frequency, which is used to evaluate the inertia support of the VSG controller to the MG system, is discussed. The simulation result demonstrates that the overshoot of the transient response can be reduced, and the system stability is improved when the proposed VSG controller is applied. The MG system based on the real-time simulator OP5600 (OPAL-RT Technologies, Montreal, QC, Canada) is carried out to verify the feasibility of the proposed VSG controller.
\end{abstract}

Keywords: microgrid control; virtual synchronous generator; power converter; power conversion

\section{Introduction}

In recent years, distributed generations based on renewable energy sources (RESs) such as photovoltaics and wind generations have been paid more attention from researchers in many parts of the world [1]. In order to improve the integration of distributed generations (DGs) into the distributed network, the MG system that is composed of different DGs, energy storage systems, and controllable loads was developed [2]. The DGs are interfaced with the MG bus using two types of power converters, namely the grid-feeding converter and the grid-forming converter [3]. Whereas the grid-feeding converter is used to regulate the power exchange with the MG system, the grid-forming converter controls the system voltage and frequency in the stand-alone mode [4].

In order to exchange power among DGs, the droop controller that imitates the steady state characteristic of a synchronous generator is usually considered as a practical method without the need of communication link. Thus, managing the power delivery of the system is costly. The droop control strategy was originally proposed for the uninterruptible power supply (UPS) system that 
contains several grid-forming units [5-7]. The UPS system is usually supplied for local loads, where the line impedances are similar. In the islanded microgrid with multiple power converters connected in parallel with loads, the line impedances are much different and dominantly resistive, which affects to the performance of voltage and frequency of the system. The $P-\omega$ droop control was extended to the parallel inverters based DGs in the stand-alone MG [8]. However, in comparison with the conventional power system where line impedances are mainly inductive, the line impedances in MG are dominantly resistive, causing several problems in the operation [9]. Consequently, several studies have been proposed for improving droop controller in the parallel stand-alone MG. Instead of using a conventional $P-\omega$ droop controller, the $P-V$ droop controller was proposed to deal with the inaccurate reactive power sharing problem [10]. In addition, a virtual impedance was introduced to imitate a virtual inductor for the impedance line [11]. On the other hand, the author in [12] proposed a virtual frame transformation to decouple the relationship between the active and reactive power and enhance the performance of the system. The adaptive decentralized droop controller was introduced to preserve power sharing stability and reduce power oscillation [13]. Furthermore, a detailed analysis of the droop controller applied in the parallel operation of DGs was discussed. The droop coefficient was also optimized by using particle swarm optimization (PSO) to improve the performance and stability of the distributed system [14].

Although the droop controller has been widely adopted in the stand-alone MG, it still has several drawbacks. In a conventional power system with massive rotating generators, the inertia stored in the rotor of synchronous generator plays an important role to maintain the system stability. However, an MG system, which is a small-scale power system, already has a relatively small inertia response [15]. In addition, the RESs are interfaced with the AC bus by the power converters based on the droop controllers, which contributes small inertia response to the MG system. After large disturbance such as generator tripping, system fault, or significant load changes in the MG system with low inertia response, the system voltage and frequency might fluctuate significantly, which may trip the generator or sensitive load [16,17]. Low inertia response of the MG system might pose challenges to the operator for maintaining the system stability $[18,19]$.

In order to tackle the problem, virtual synchronous generator (VSG) control, which provides virtual inertia to the MG system, was first introduced in [20]. By imitating the steady state and the transient behavior of the synchronous generator, the total inertia of the MG system can be increased [21]. The detailed analysis of VSG control and droop control was studied in [22], showing the effectiveness of the VSG control over droop controller in term of the stability field. Various studies have proposed, taking the advantage of VSG controller for the MG in both grid-feeding converter and grid-forming converter [23,24]. The author in [25] introduced a VSG-based grid-feeding converter for a short-term energy buffer to smooth the power fluctuation of DGs. Besides, a modification of VSG with frequency deviation for the grid-forming converter was proposed to improve the transient response of the MG system [26]. Additionally, the parameters of the VSG controller are designed and analyzed in $[27,28]$. However, comparing to the MG system with only grid-forming or grid-feeding converters, the overshoot of the transient response in the MG system with both power converters is much higher due to the different response time of two converters [29].

In previous studies, the transient response of the power converters was not considered in both the droop controller and the conventional VSG controller. In order to address this gap, the major contribution of this study is to propose a VSG control for reducing the transient response of the power converters in the MG system. The output power derivation of power converters is added in the VSG controller to improve the primary response of active power and frequency under the load transient. The small signal analysis of the conventional VSG controller and proposed VSG controller is carried out to show the improvement of the transient response in the case of using the proposed VSG controller. The root locus of the systems is obtained from the mathematical model of both methods to evaluate the effectiveness of the proposed VSG controller. An analysis of virtual inertia and virtual damping 
factor of the VSG controller is studied to demonstrate that the system stability can be improved by changing the virtual damping factor and virtual inertia factor.

The rest of this paper is organized as follows: Section 2 briefly presents the structure of inverter-based distributed generator in the stand-alone MG. In Section 3, the principle of the proposed VSG controller is discussed. System parameters and simulation results of the proposed VSG controller are analyzed in Section 4. Finally, the conclusion of the paper is given in Section 5.

\section{Inverter-Based Distributed Generation}

The structure of an inverter-based DG is illustrated in Figure 1. In this structure, a DG, which can be a photovoltaic, a wind turbine, or an energy storage system, is connected to the AC bus through the converter. Inverter-based DG can be classified into two types: a grid-feeding converter and a grid-forming converter. The grid-feeding converter can be considered as a current source connected with high impedance in parallel to control the power exchange between MG and the utility grid. Nevertheless, it has no ability to control the system frequency and voltage. Thus, the grid-feeding converter cannot operate individually without any support from a synchronous generator or the other types of converter. On the other hand, the grid-forming converter is designed as a voltage source connected with low impedance in series. It plays an important role in regulating the voltage and frequency of the system in stand-alone operation. Therefore, the AC voltage of the grid-forming converter can be considered as the reference of voltage for other grid-feeding converters. In this study, a combination of DGs based on the grid-feeding converter and the grid-forming converter is focused. The detail control scheme for each type of converters is presented in the following subsections.

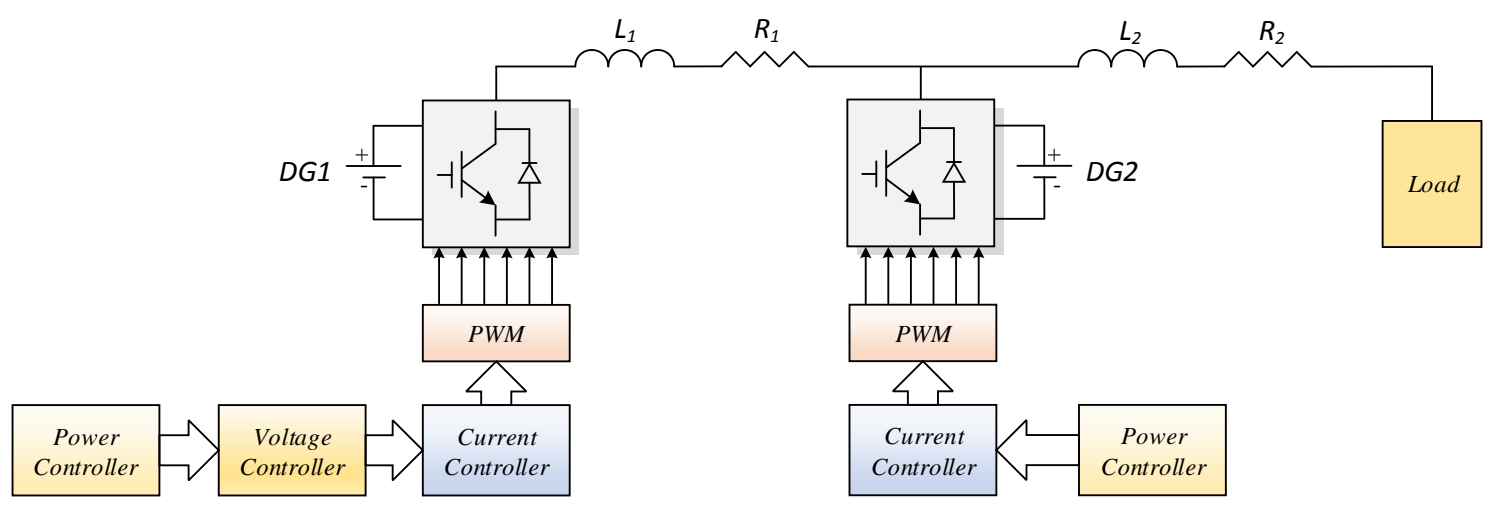

Figure 1. Structure of inverter based distributed generation in MG system.

\subsection{Grid-Forming Converter}

The control scheme for the grid-forming converter can be divided into three cascaded controllers, including power controller, voltage controller, and current controller, as described in Figure 2. The outer control loop consists of active and reactive power controller, which generates the reference angle $\theta$ and the amplitude $E^{*}$ for the reference output voltage. Whereas the VSG controller is applied to the active power controller to generate the reference angle $\theta$, the droop controller is employed in the reactive power controller to regulate the amplitude $E^{*}$ for the reference of output voltage. The reference of output voltage $v_{a b c}^{*}$ regulated from the power controller is calculated by the following equations:

$$
\begin{gathered}
v_{a}^{*}=E^{*} \cos (\theta) \\
v_{b}^{*}=E^{*} \cos \left(\theta+\frac{2 \pi}{3}\right) \\
v_{c}^{*}=E^{*} \cos \left(\theta-\frac{2 \pi}{3}\right)
\end{gathered}
$$




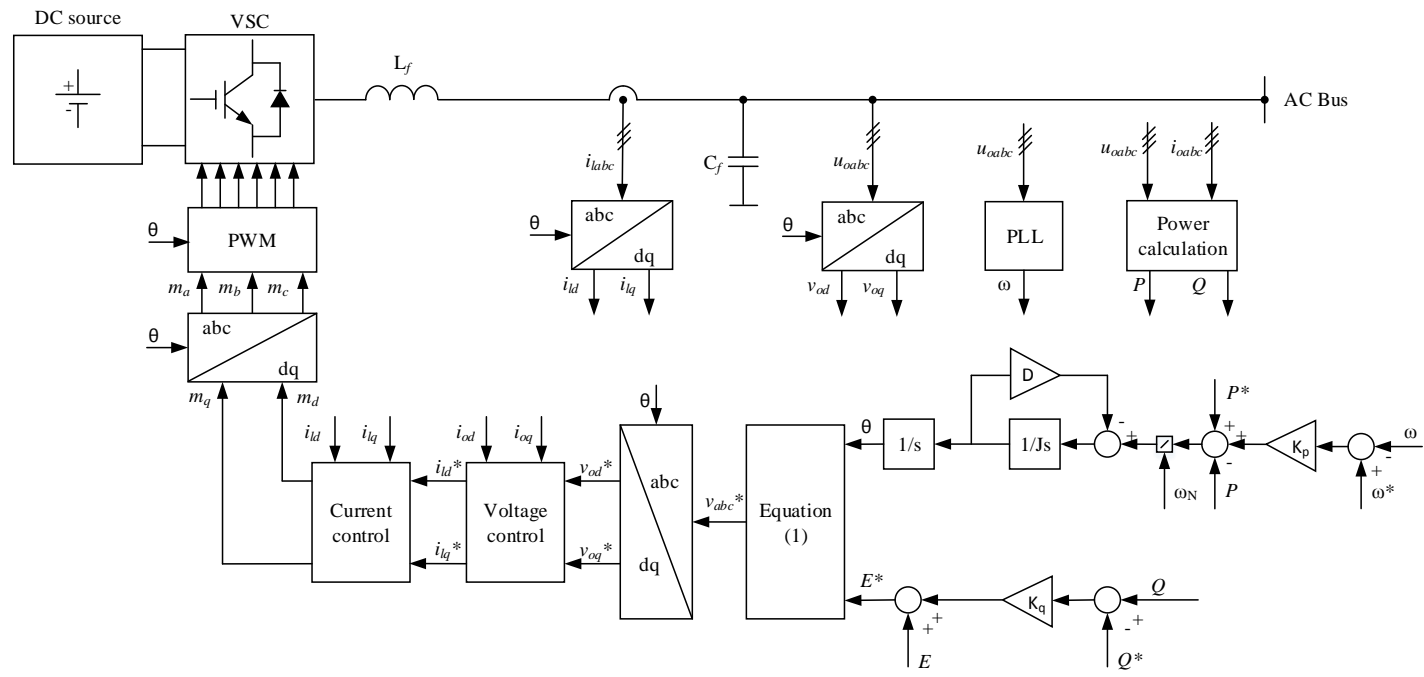

Figure 2. Control scheme of the virtual synchronous generator control-based grid-forming converter.

The output voltage reference is transferred from $a b c$ reference frame to $d q$ reference frame before sending to the inner controllers. The inner control loop contains two controllers, namely current controller and voltage controller. Whereas the voltage controller regulates the amplitude of voltage determined by the VSG controller, the currents controller conducts the current supplied by the converter to match its reference value. In other words, the current flowing through the inductor filter $L_{f}$ is conducted to regulate the voltage on the capacitor filter $C_{f}$. The structure of inner controller is depicted in Figure 3. The reference value of the current controller $i_{l d}^{*}$ is compared with the measured current $i_{l d}$ flowing through the inductor filter. Then, the error signal is input to the PI controller. The output of the current controller is the modulating signal, which is utilized to compare with the carrier signals to determine the switching time of the insulated gate bipolar transistor (IGBT) switches. The output of the current controller is calculated in the following equations:

$$
\begin{aligned}
& m_{d}=v_{o d}-\omega i_{l q} L_{f}+k_{p c}\left(i_{l d}^{*}-i_{l d}\right)+k_{i c} \int\left(i_{l d}^{*}-i_{l d}\right) d t \\
& m_{q}=v_{o q}+\omega i_{l d} L_{f}+k_{p c}\left(i_{l q}^{*}-i_{l q}\right)+k_{i c} \int\left(i_{l q}^{*}-i_{l q}\right) d t
\end{aligned}
$$

where $k_{i v}$ and $k_{i c}$ are the proportional and integral components of current controller and $m_{d}$ and $m_{q}$ are the modulating signals in the $d q$ reference frame.

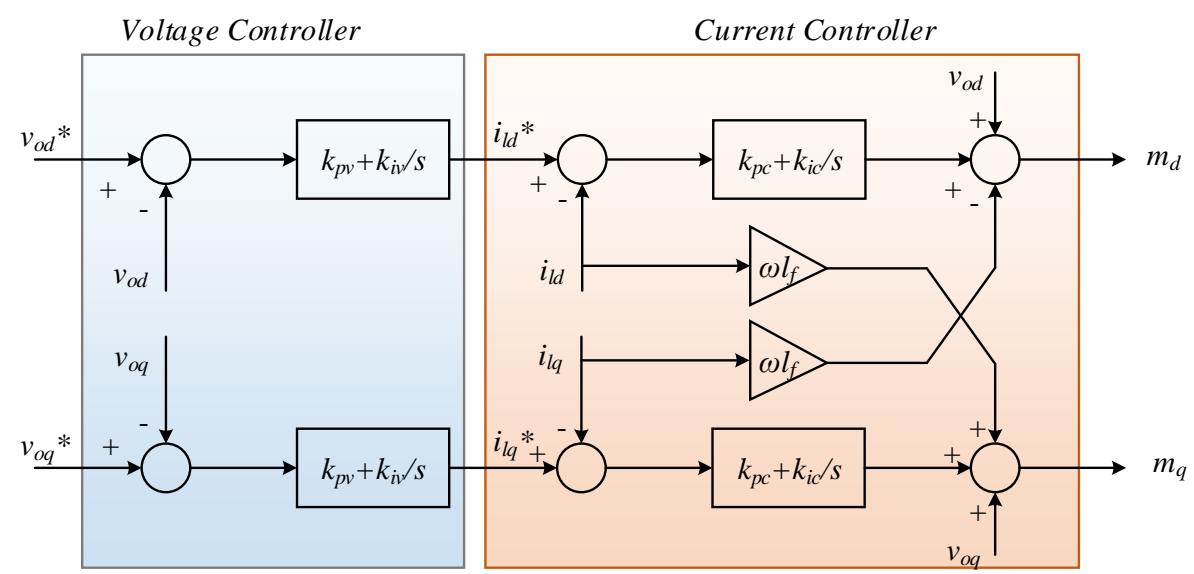

Figure 3. Control scheme of inner controller. 
Regarding the voltage controller, it is employed to control the output voltage of the MG. Similar to the current controller, the set value of the voltage controller $v_{o d}^{*}$ is also compared with the measured voltage $v_{o d}$ of the AC bus and then input to the proportional-integral (PI) controller. However, the output signals of voltage controller $i_{l d}^{*}$ and $i_{l q}^{*}$ are the reference values of current controller, as shown in Figure 3. The current reference can be treated in (6) and (7).

$$
\begin{aligned}
& i_{l d}^{*}=k_{p v}\left(v_{o d}^{*}-v_{o d}\right)+k_{p c} \int\left(v_{o d}^{*}-v_{o d}\right) d t \\
& i_{l q}^{*}=k_{p v}\left(v_{o q}^{*}-v_{o q}\right)+k_{p c} \int\left(v_{o q}^{*}-v_{o q}\right) d t
\end{aligned}
$$

where $k_{p v}$ and $k_{p c}$ is the proportional and integral components of voltage controller.

The conventional droop controller is applied to the reactive power controller in order to determine the amount of reactive power that can be transferred through the AC bus, based on the fluctuation of AC voltage. Figure 4 shows the control scheme of reactive power controller. The output of reactive power controller is the voltage reference which input to the voltage controller. It is given as follows:

$$
E^{*}=E-k_{q}\left(Q^{*}-Q\right)
$$

The relation between reactive power and AC voltage is described through a droop coefficient, which can be defined by Equation (9).

$$
k_{q}=\frac{V_{\max }-V_{\min }}{Q_{\max }-Q_{\min }}
$$

where $V_{\max }$ and $V_{\min }$ are the maximum and minimum AC voltage that can be allowed and $Q_{\max }$ and $Q_{\text {min }}$ are the maximum and minimum reactive power transferred through the AC bus.

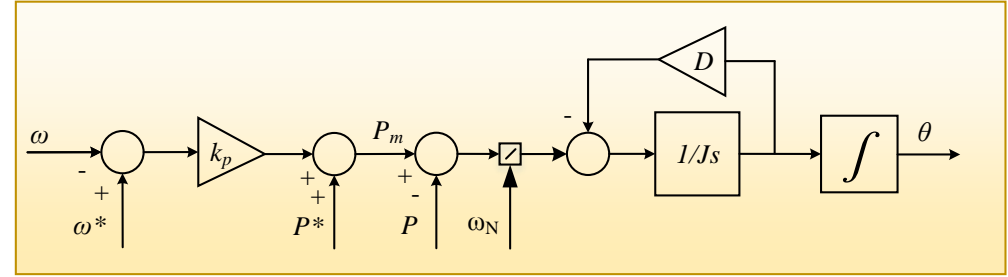

(a)

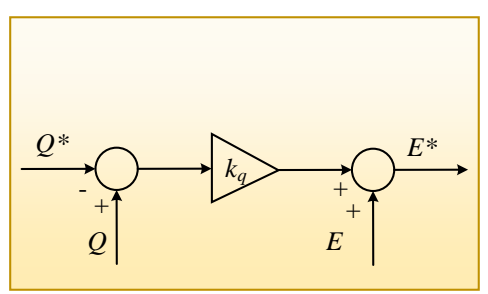

(b)

Figure 4. Control scheme: (a) virtual synchronous generator (VSG) controller; (b) $Q-V$ droop controller.

Regarding the active power controller, the control scheme of conventional virtual synchronous generator control method applying to the grid forming converter is described in Figure 4. The main component which can be used to distinguish the VSG controller and droop controller is the swing equation. It can be described as follows:

$$
\begin{gathered}
P_{m}=P+J \omega_{N} \frac{d \omega}{d t}+D \omega_{N}\left(\omega-\omega_{N}\right) \\
\frac{d \theta}{d t}=\omega
\end{gathered}
$$

where $P_{m}$ the mechanical power generated from the governor, $P$ measured active power of the inverter, $J$ the virtual inertia, $D$ is the damping factor, $\omega$ is the angular frequency, $\omega_{N}$ is the rated angular frequency of the system, and $\theta$ is the electrical angle.

The mechanical power $P_{m}$ generated from the governor is described as

$$
\left(\omega^{*}-\omega\right)=-k_{p}\left(P^{*}-P_{m}\right)
$$




\subsection{Grid-Feeding Converter}

The grid-feeding converter can be controlled as a current source, connecting with the AC bus through high parallel impedance. While the grid-forming converter can maintain the voltage and frequency of the MG, the grid-feeding converter regulates power sharing with other DGs. The structure of the controller of grid-feeding converter is shown in Figure 5. The grid-feeding converter also consists of three cascaded control loops: droop controller, power controller, and current controller. Whereas the current controller of grid-feeding converter is similar to that of grid-forming converter, the power control is used to control the power exchange with another distributed generator, which is determined by the droop controller. The equation of droop controllers for active power-frequency and reactive power-voltage are given as follows:

$$
\begin{aligned}
& \left(\omega^{*}-\omega\right)=-k_{p}\left(P^{*}-P\right) \\
& \left(V^{*}-V\right)=-k_{q}\left(Q^{*}-Q\right)
\end{aligned}
$$

where $k_{p}$ and $k_{q}$ are droop coefficients of $P-\omega$ droop controller and $Q-V$ droop controller.

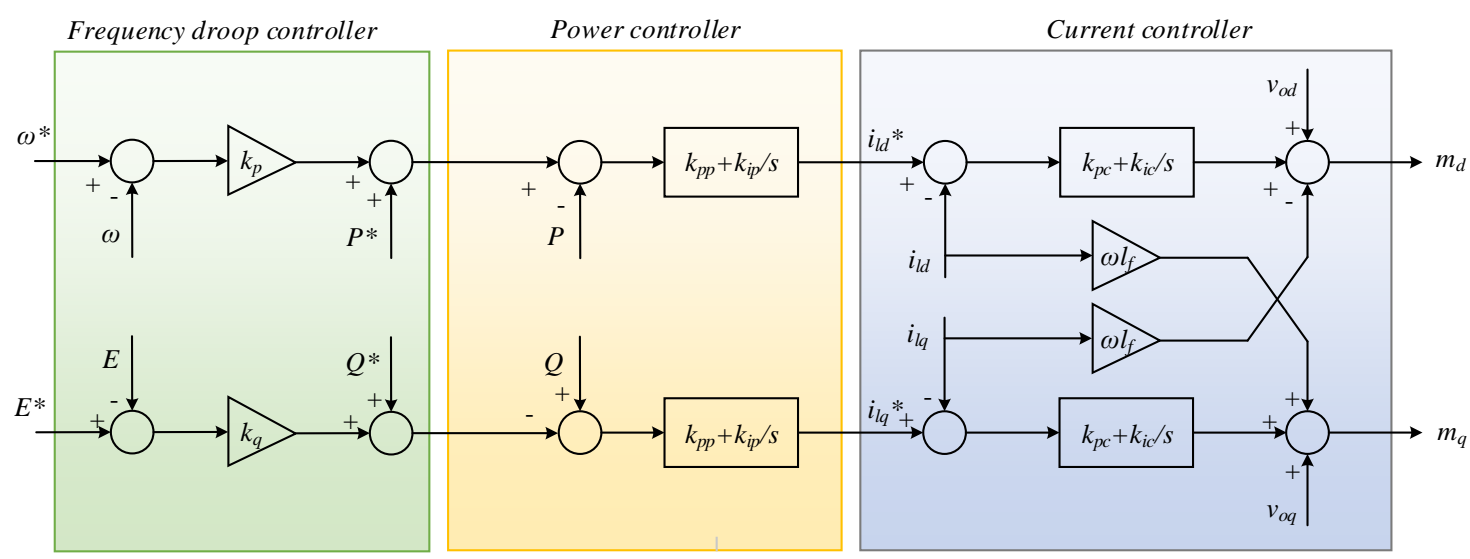

Figure 5. Control scheme of grid-feeding converter.

\section{Proposed Virtual Synchronous Generator Control}

The control scheme of proposed VSG controller is illustrated in Figure 6. The derivative component is added to the governor block before going to the swing equation. In the steady state, the active power derivation is equaled to zero because the mechanical power generated from the governor is unchanged. Therefore, the dynamic response of active power is not affected. However, during the transient state, the active power is fluctuated, which makes the derivative component of active power varied proportionally. Hence, the overshoot of active power can be reduced by subtracting the active power derivation. In addition, a rating coefficient is multiplied with the active power derivation to improve the efficiency of power derivation. The swing equation of the proposed VSG controller is modified as follows:

$$
P_{m}-P=k_{d} \frac{d P}{d t}+J \omega_{N} \frac{d \omega}{d t}+D \omega_{N}\left(\omega-\omega_{N}\right)
$$

where $\frac{d P}{d t}$ is the active power derivation; $k_{d}$ is the derivative coefficient. 


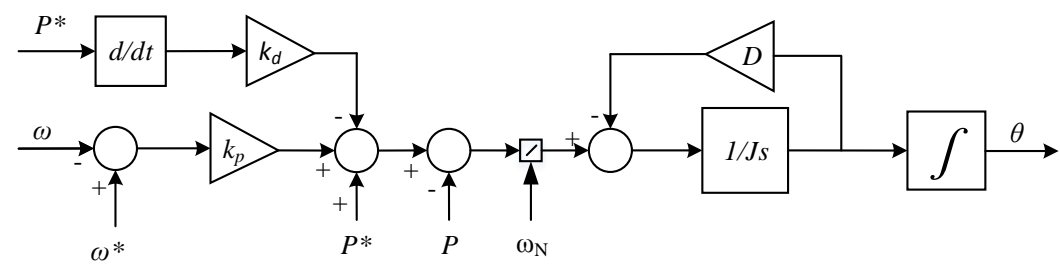

Figure 6. Control scheme of VSG controller.

The modification of swing equation presented in (15) can be transferred to the Laplace domain as follows:

$$
\left(\Delta P^{*}-\Delta P-k_{d} s P\right) \frac{1}{\omega_{N}(J s+D)} \frac{K}{s}=\Delta P
$$

where $\omega_{N}$ is the nominal angular frequency of the MG system and $K$ is the rating coefficient of active power and frequency.

From (16), the transfer function of the proposed VSG controller can be described in (17) and the small signal model is obtained from the transfer function is illustrated in Figure 7:

$$
\frac{\Delta P}{\Delta P^{*}}=\frac{K}{\omega_{N}(J s+D)+K\left(k_{d} s+1\right)}
$$

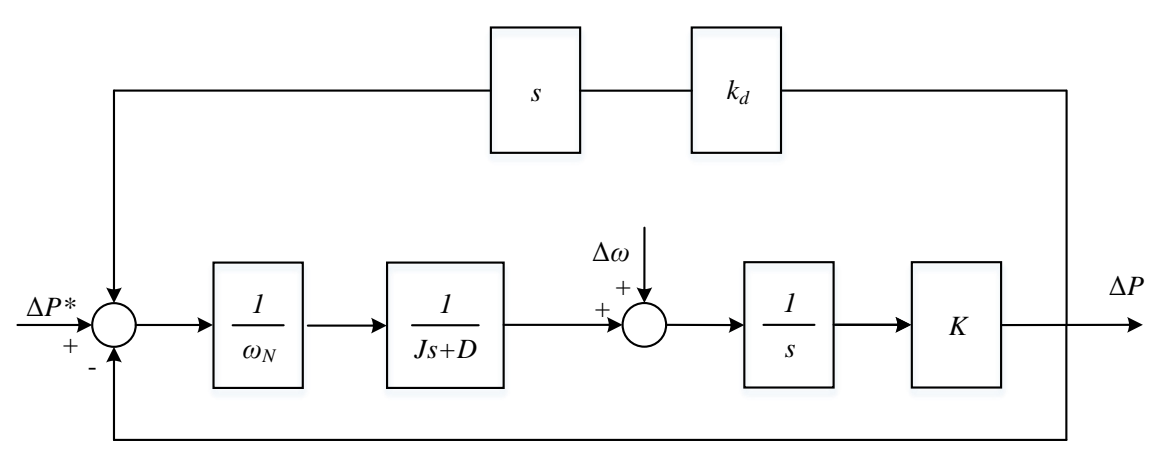

Figure 7. Small signal model of active power of proposed VSG controller.

Similarly, the small signal model of the conventional VSG controller described in Figure 8 is also obtained from its closed loop transfer function below:

$$
\frac{\Delta P}{\Delta P^{*}}=\frac{K}{\omega_{N}(J s+D)+K}
$$

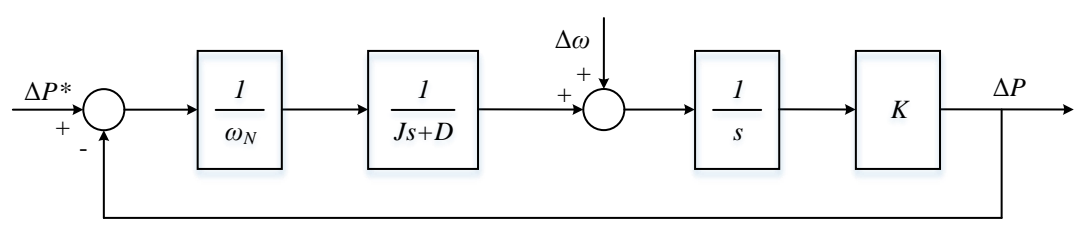

Figure 8. Small signal model of active power of the VSG controller.

The root locus plot obtained from the small signal model is shown in Figure 9. In this figure, the system poles of the conventional VSG controller and the proposed VSG controller are compared in case of increasing the rotational inertia. It is observed that when the inertia is increased from $J=10$ to $J=2000$, the system poles of the conventional VSG controller and the proposed VSG controller move far away from the real axis, which illustrates the improvement of the overshoot in the transient response and stability margin of the MG system. 


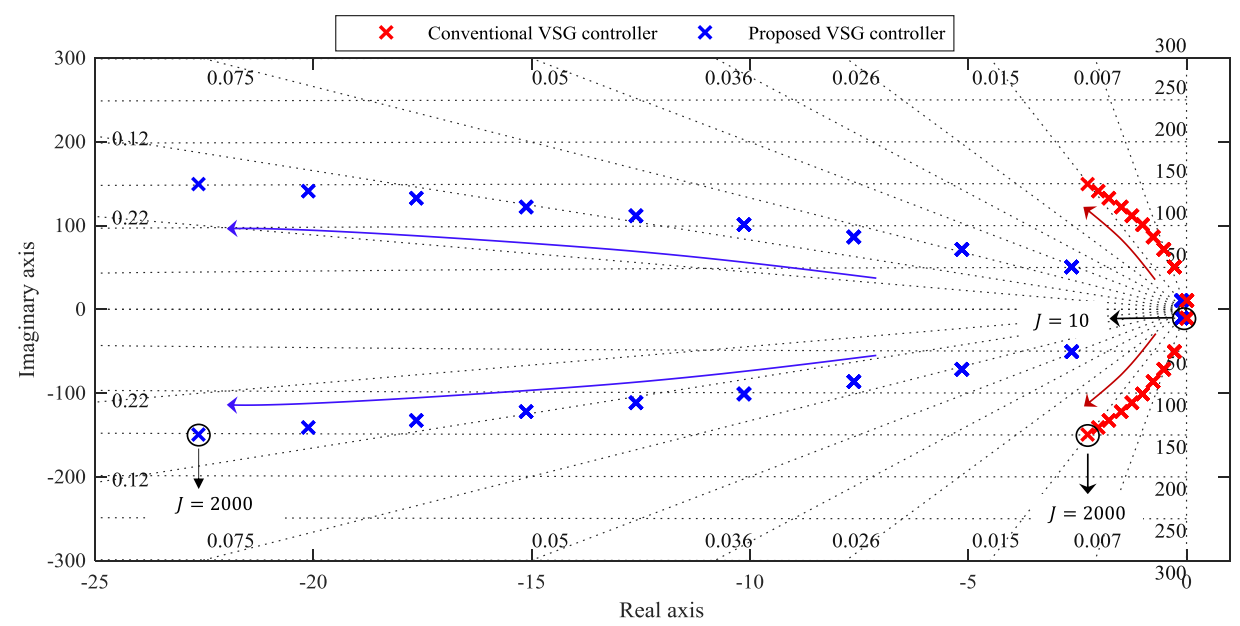

Figure 9. Root locus plot of the converters with conventional and proposed VSG control.

In addition, it can be seen from Figure 10 that when the derivative coefficient $k_{d}$ is increased, the proposed VSG controller have smaller oscillation and the settling time of the system is also increased compared to that of the conventional droop controller. Furthermore, similar with the rating coefficient, the settling time of the system is also increased by increasing the damping factor $D$, as described in Figure 11 .

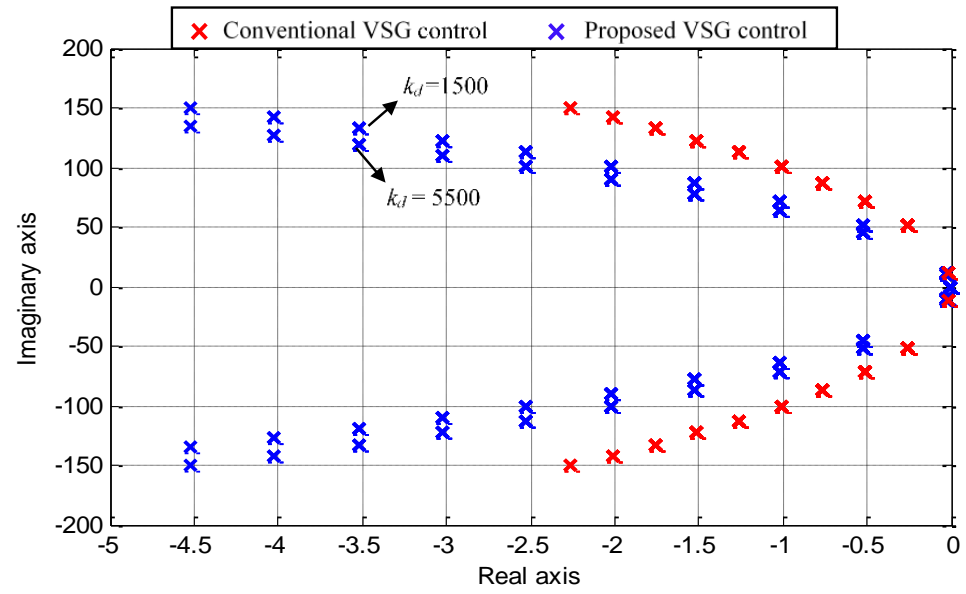

Figure 10. Root locus plot of the converters when increasing the derivative coefficient.

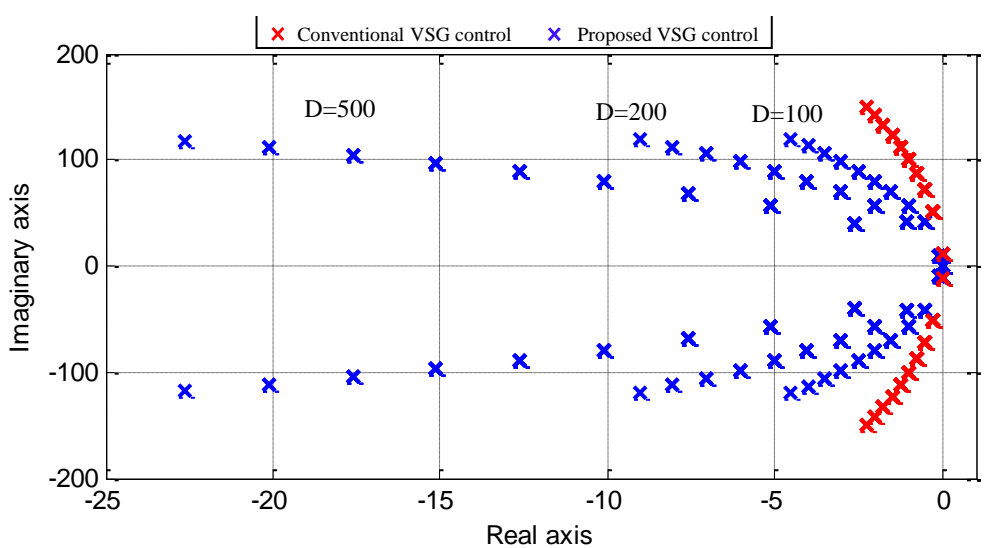

Figure 11. Root locus plot of the converters when increasing the damping factor. 


\section{Simulation Results}

A detailed simulation is executed using SimPowerSystems toolbox of Matlab/Simulink (version R2011b, MathWorks, Natick, MA. USA) environment in order to verify the effectiveness of the proposed VSG control. In this simulation, a low voltage MG, which consists of two inverter-based DGs and load, is studied. The electrical load is connected in parallel with two DGs through impedance lines, which comprises both resistive and inductive components, as shown in Figure 1. The impedance lines are considered as mainly resistive. The droop coefficients of active power and voltage are designed to ensure that the frequency of the system is fluctuated from $59.8 \mathrm{~Hz}$ to $60.2 \mathrm{~Hz}$. The MG is designed to operate at $10 \mathrm{kHz}$ of switching frequency to avoid the high frequency oscillation. The detailed parameters of the MG are listed in Table 1.

The simulation is divided to several time intervals. Initially, the MG operates with a small load (load 1). After that, a big load change (load 2) is connected to the MG at $8 \mathrm{~s}$ before cutting off from the system at $14 \mathrm{~s}$. To evaluate the dynamic performance of the active power and frequency under the loading transition, the proposed VSG control is applied to the grid-forming converter and then is compared with the droop controller and conventional VSG controller.

Table 1. System parameters.

\begin{tabular}{cccc}
\hline Parameters & Values & Parameters & Values \\
\hline DC-link voltage & $380 \mathrm{~V}$ & Load 1 & $5 \mathrm{~kW}$ \\
AC bus voltage & $220 \mathrm{~V}$ & Load 2 & $10 \mathrm{~kW}$ \\
System frequency & $60 \mathrm{~Hz}$ & Resistive impedance & $0.355 \mathrm{Ohm}$ \\
Frequency deviation & $\pm 0.2 \mathrm{~Hz}$ & Inductive impedance & $0.15 \mathrm{mH}$ \\
Switching frequency & $10 \mathrm{kHz}$ & Frequency droop gain & $4.189 \times 10^{-4}$ \\
Virtual inertia & $32 \mathrm{~kg} \cdot \mathrm{m}^{2}$ & Voltage droop gain & $3 \times 10^{-2}$ \\
\hline
\end{tabular}

It can be observed from Figure 12 that after the large load change at $8 \mathrm{~s}$, the active power in case of using droop control, conventional VSG control, and proposed VSG control methods differs significantly. When droop controller is applied, the transient response of active power has low inertia. In addition, due to the different inertia between two types of converter, oscillation occurs. Thus, this results in a high overshoot of the dynamic response of active power. The inertia of the system can be supported by applying the conventional VSG controller because it has the ability to provide inertia virtually to the MG. However, although the lack of inertia can be solved in this case, the overshoot is still larger compared to that of the droop controller. By using the proposed VSG controller, the inertia support feature inherited from the conventional VSG controller is remained. Moreover, the overshoot of the proposed method is considerably reduced compared to that of the droop controller and conventional VSG controller. When load 2 is cut off from the MG at $14 \mathrm{~s}$, the proposed VSG method shows a better performance compared to that of other methods. The active power has higher inertia compared to the droop controller, and the overshoot is reduced significantly compared to that of the conventional VSG controller.

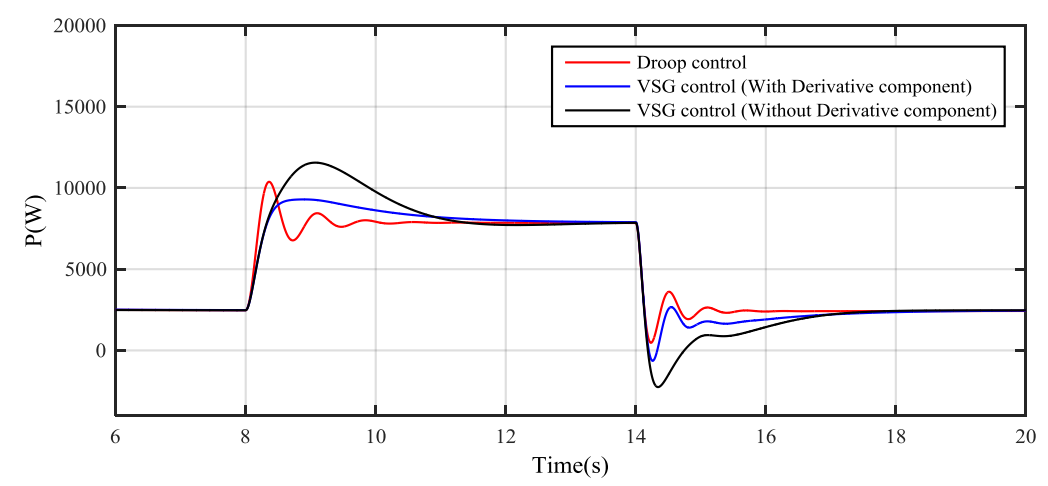

Figure 12. Active power of grid-forming converter. 
With regard to the grid feeding converter, it can be seen from Figure 13 that there is a trade-off of active power between the two converters. Whereas the dynamic response of the grid-feeding and grid-forming converter looks similar to high overshoot and oscillation when the droop controller is applied, there is no overshoot in the active power in case of applying the conventional VSG and the proposed VSG controller. Besides that, although VSG control is not applied to the grid-feeding converter, the inertia of active power is also improved because the total inertia of the system is increased when VSG control is applied to the grid-forming converter [24].

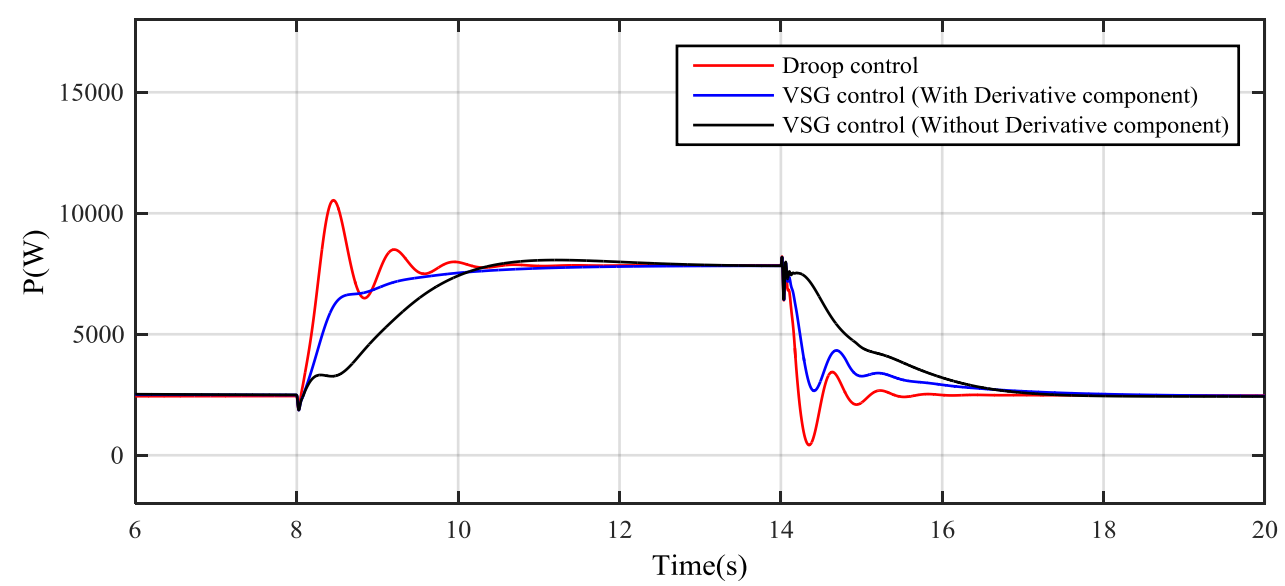

Figure 13. Active power of grid-feeding converter.

Additionally, the inertia of the system can be observed clearly in the frequency response, which is depicted in Figure 14. When the droop controller is utilized for the grid-forming converter, in the steady state, the frequency is fluctuated within the limited range which is allowed from $59.8 \mathrm{~Hz}$ to $60.2 \mathrm{~Hz}$. However, in the transient state, the frequency response fluctuated over $59.8 \mathrm{~Hz}$ when load 1 is connected at $8 \mathrm{~s}$. Therefore, the system stability can be affected and tends to be unstable. Nonetheless, applying the conventional VSG controller and proposed VSG controller can increase the total inertia and reduce overshoot and low frequency oscillation of the system.

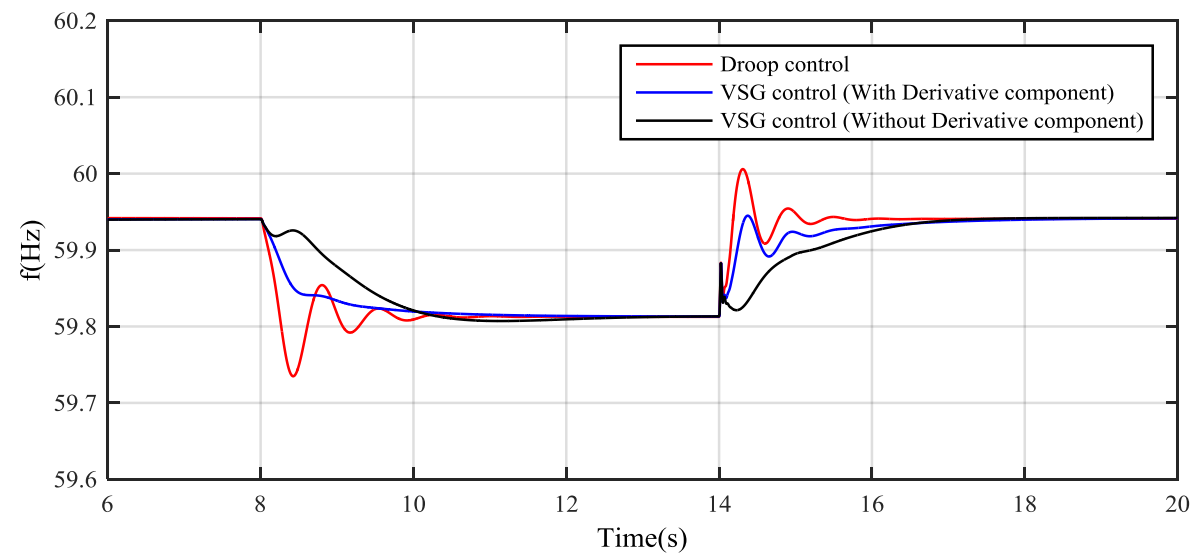

Figure 14. System frequency.

On the other hand, virtual inertia and the virtual damping factor play an important role in improving the stability of the system. In order to fully understand their impacts on the MG, the analysis of these components is investigated. The MG is first simulated with $J=32$ and $D=50$. After that, whereas the damping factor is remained unchanged, the virtual inertia is increased to $J=40$ and $J=48$, respectively. Figure 15 describes the active power performance of the grid-forming converter 
at various inertia values. It can be seen that even though the overshoot of the grid-forming converter is slightly increased, the system is provided more inertia during the transient time. It is also true for the dynamic response of the grid-feeding converter, as shown in Figure 16. The inertia of the system is observed clearly through the frequency response, as described in Figure 17. An increase of virtual inertia value leads to the growth of total system inertia.

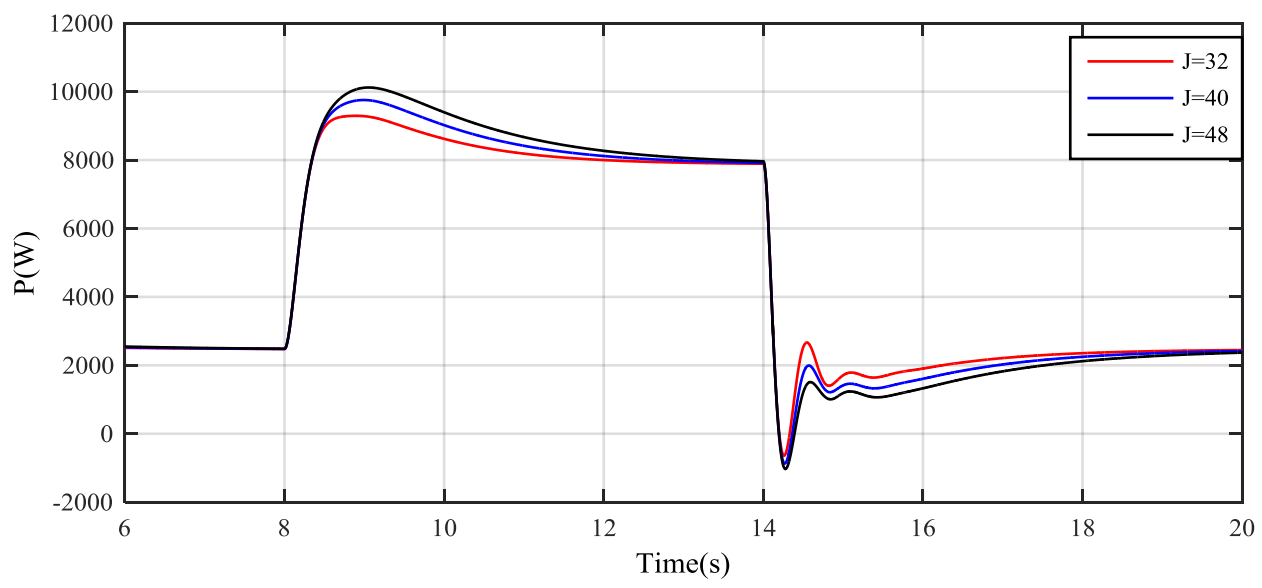

Figure 15. Active power of grid-forming converter with different virtual inertia.

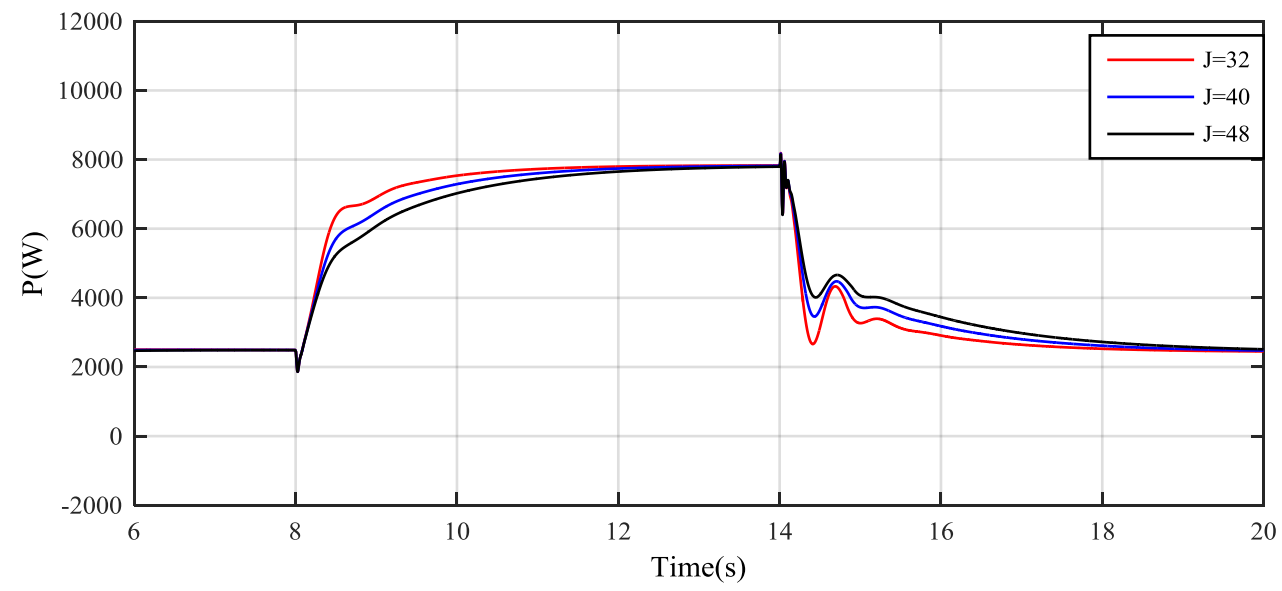

Figure 16. Active power of grid-feeding converter with different virtual inertia.

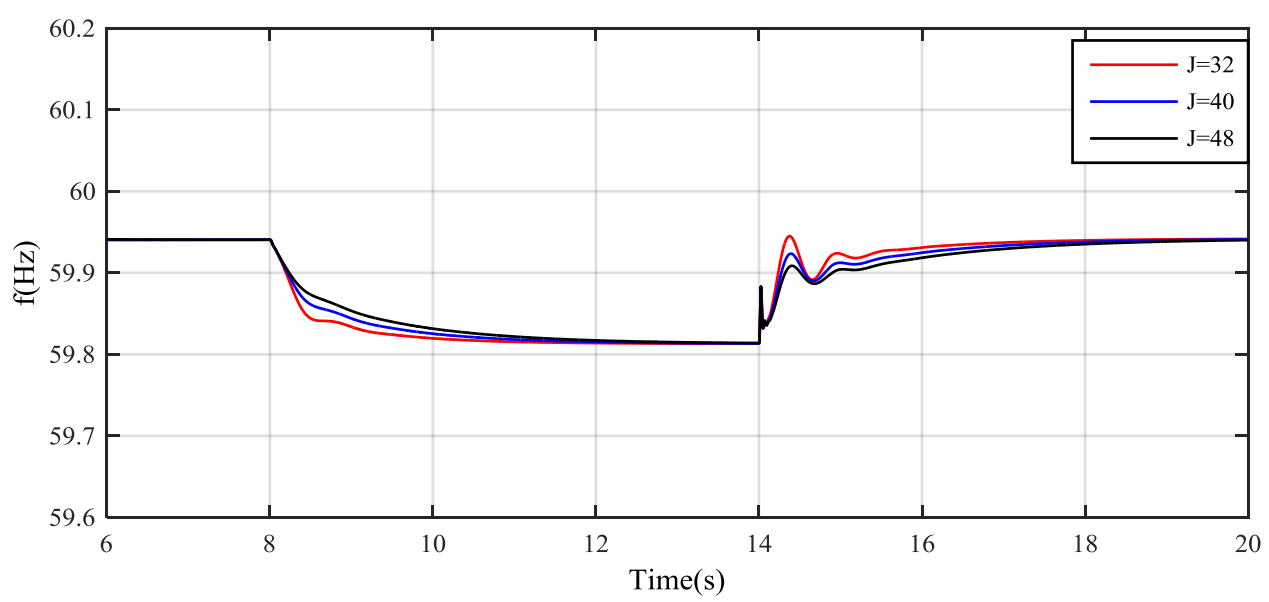

Figure 17. System frequency with different virtual inertia. 
With regard to the virtual damping factor, as can be observed in Figures 18 and 19, there is a trade-off between the two DGs. In this case, the virtual damping factor is increased from $D=50$ to $D=500$ and $D=1000$, respectively. While the active power of the grid-forming converter is increased, that of the grid-feeding converter is decreased. The system frequency is decreased, which avoids the system to be unstable because the frequency derivation is limited, as shown in Figure 20.

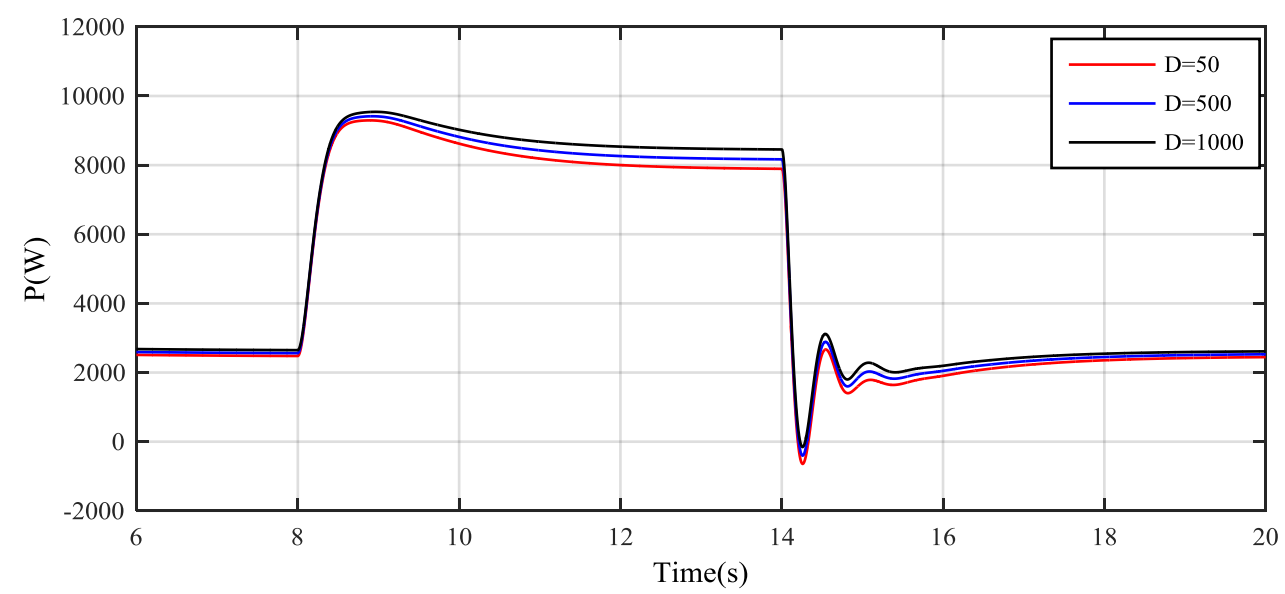

Figure 18. Active power of grid-forming converter with different virtual damping factors.

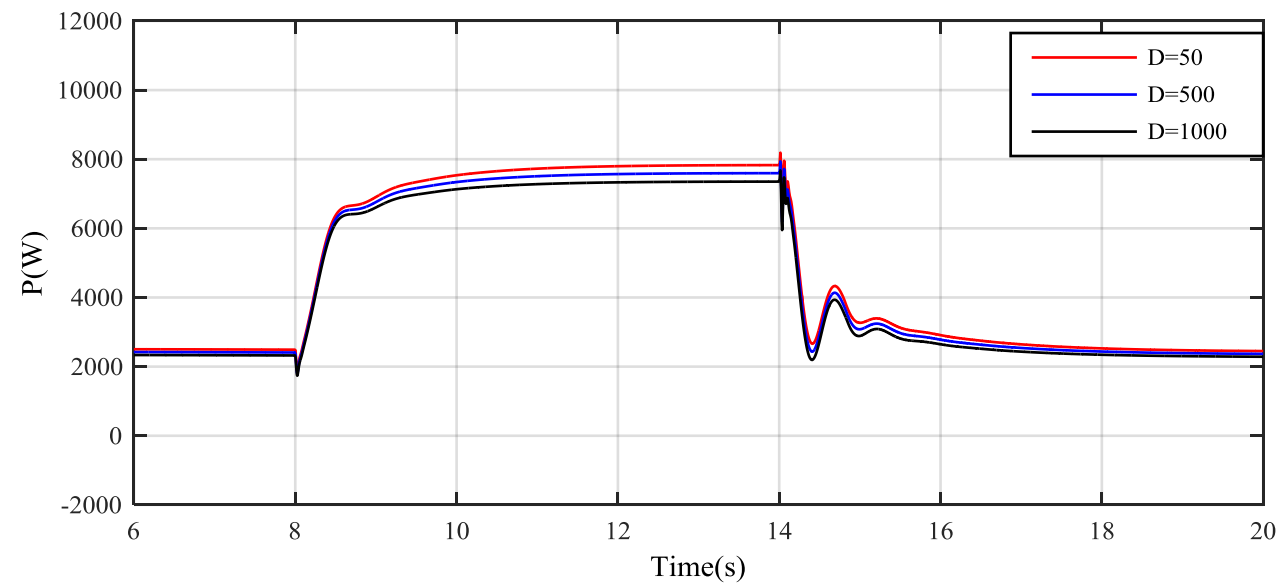

Figure 19. Active power of grid-feeding converter with different virtual damping factors.

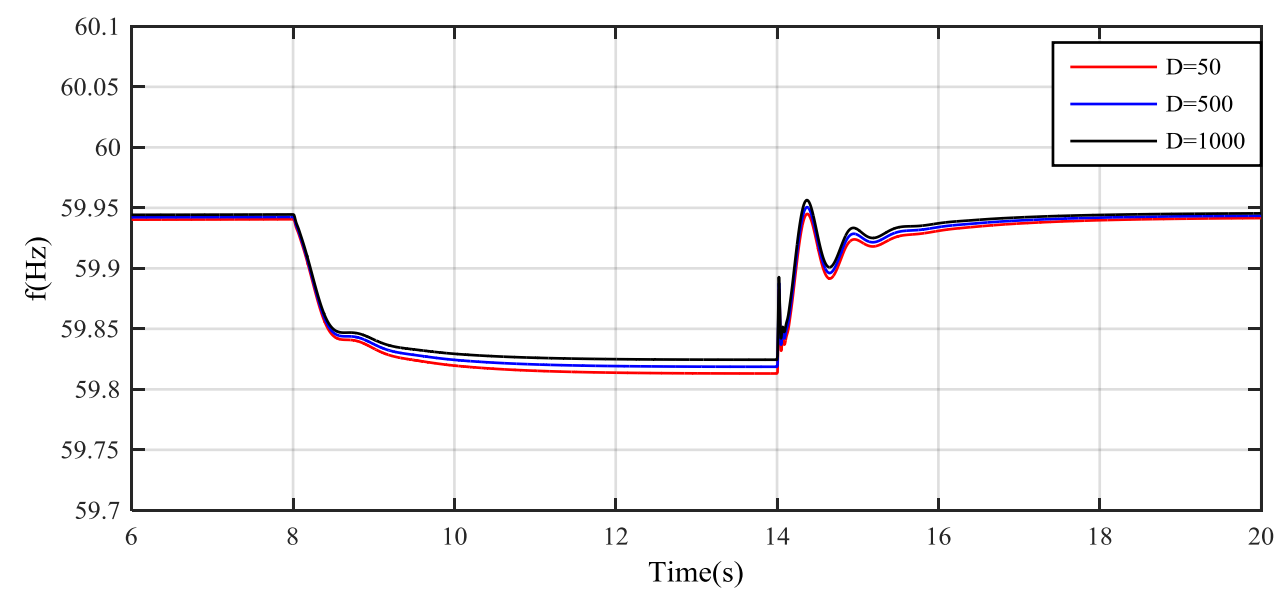

Figure 20. System frequency with different virtual damping factors. 
The inertia response is observed clearly in the derivation of frequency $d f / d t$, which is illustrated in Figure 21. It can be seen that during the transient states at $8 \mathrm{~s}$ and $14 \mathrm{~s}$, the frequency derivation of droop controller has the highest overshoot. However, when the conventional VSG controller and proposed VSG controller are applied, the derivation of frequency varies slower than that of the droop controller, and its overshoot is slightly decreased.

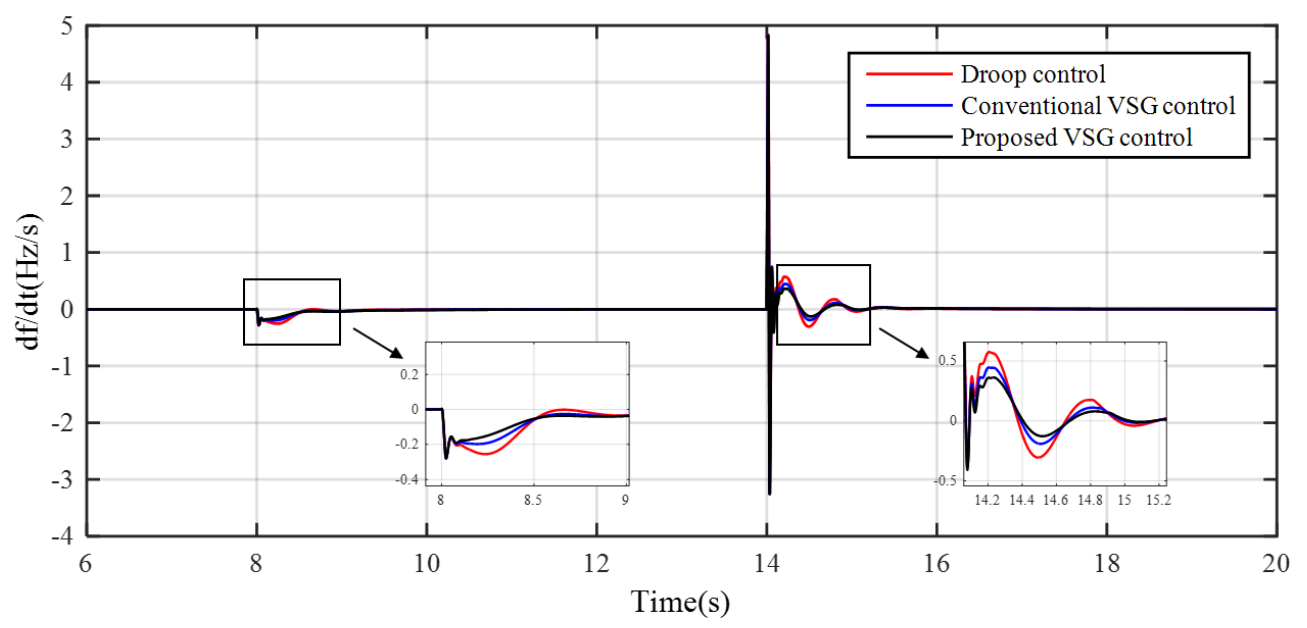

Figure 21. Derivative component of system frequency.

\section{Experimental Results}

The complete MG system with the proposed VSG controller is built and tested experimentally using real time simulation system (OPAL-RT). The structure of the MG performed in the experiment is similar with that of the simulation. Due to the mismatch of line impedances, the inaccurate reactive power sharing occurs as a serious problem in the MG system. In order to deal with this problem, the virtual impedance method is applied for the grid-forming converter. The detail of virtual impedance is introduced, following the equation below.

$$
v_{r e f}=v_{a b c}^{*}-Z_{v i r}(s) i_{o}
$$

where $Z_{v i r}$ is the virtual output impedance, $v_{\text {ref }}$ is the reference of output voltage obtained by the using virtual impedance, $v_{a b c}^{*}$ is the output voltage reference achieved by conventional $P-\omega$ droop controller, and $i_{o}$ is the output current of the grid-forming converter.

If the virtual inductive component $L_{v i r}$ is included to the virtual impedance, as presented.

$$
Z_{\text {vir }}=s L_{\text {vir }}
$$

It can be seen from Equation (20) that the reference of output voltage is proportionally changed depending on the derivation of output current. Thus, the effect of the resistive component on the output voltage can be reduced, and the active power can be shared equally. In this part, a comparison between the proposed VSG controller and the droop controller considering virtual impedance control is presented.

It is obviously seen from Figures 22 and 23 that when the transient response of reactive power when the proposed VSG controller is applied, the transient response of power is reduced in comparison with that of the droop controller. 


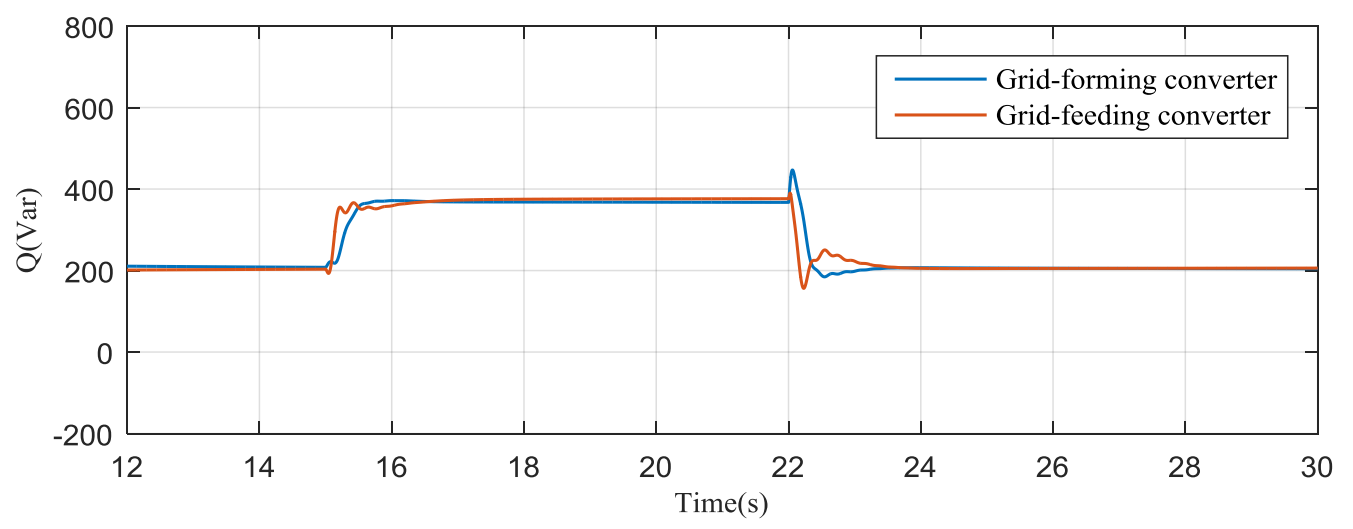

Figure 22. Reactive power of the proposed VSG control with virtual impedance.

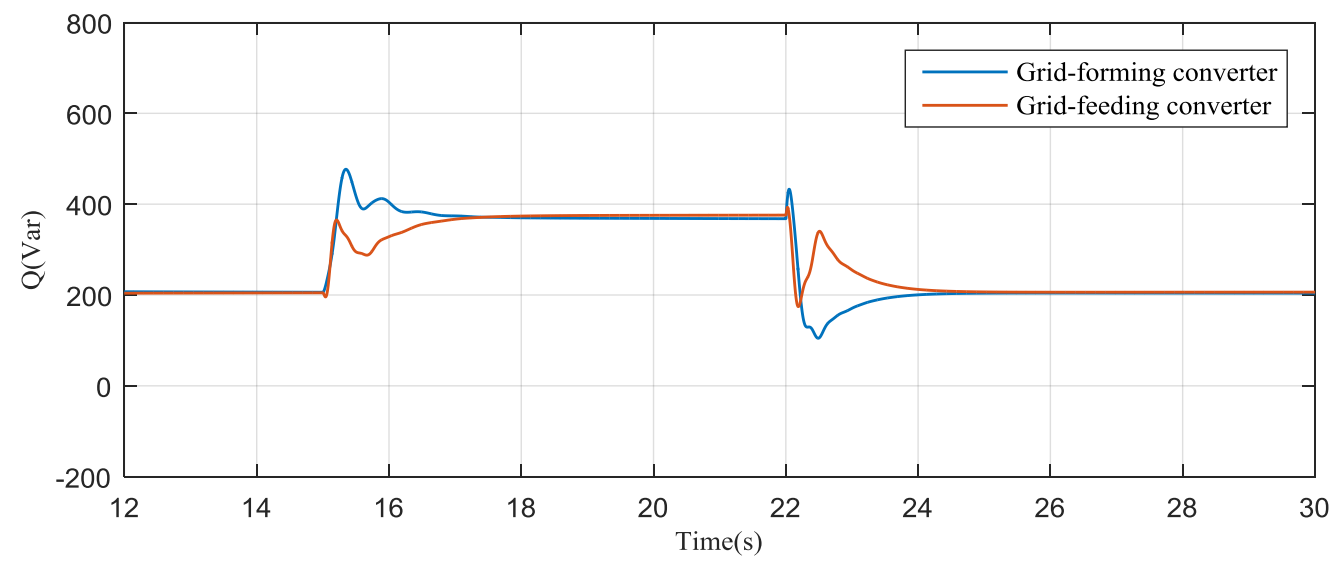

Figure 23. Reactive power of the droop control considering virtual impedance.

With regard to the active power, Figure 24 shows that after a load change at $15 \mathrm{~s}$, the transient response of active power of grid forming converter is slightly reduced when the proposed VSG control is applied. By contrast, the transient response of grid-feeding converter presents much better improvement in case of adopting the proposed VSG controller, as shown in Figure 25.

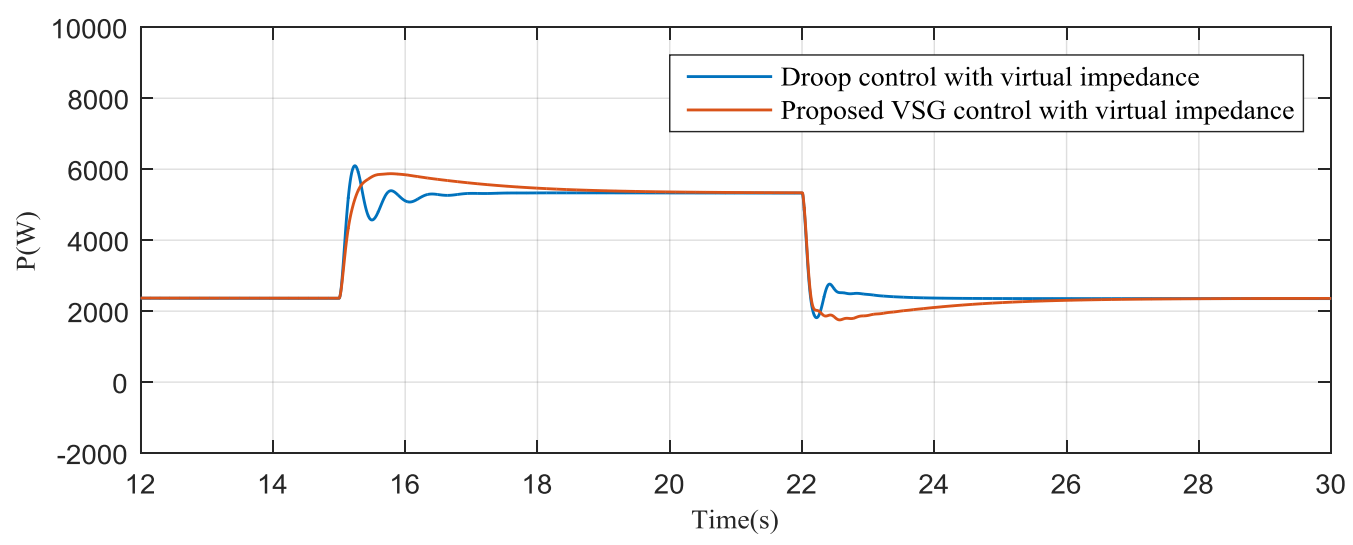

Figure 24. Active power of the grid-forming converter. 


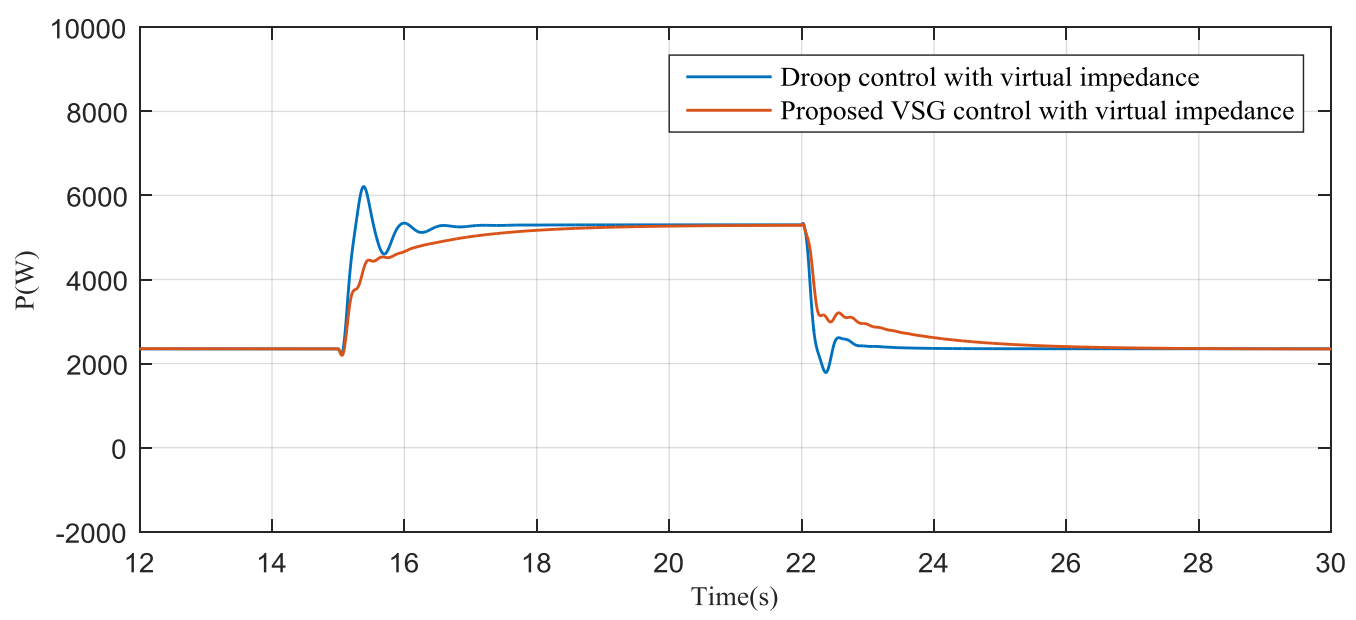

Figure 25. Active power of the grid-feeding converter.

Regarding frequency response, it can be seen from Figure 26 that the by applying the proposed VSG control, the total inertia of the system is enhanced compared to that of the droop control with virtual impedance. In addition, the peak of overshoot in the frequency response is significantly reduce. Therefore, this avoids the over maximum and minimum frequency deviation and enhanced the stability of the system.

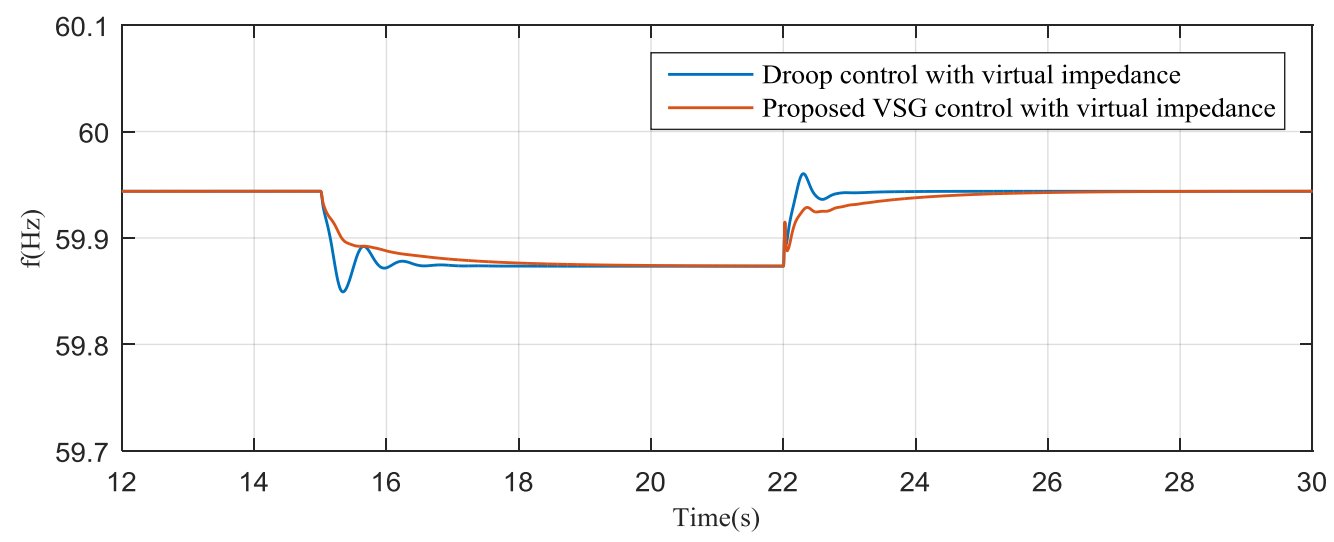

Figure 26. System frequency.

\section{Conclusions}

In this study, an improved VSG controller was proposed for improving the transient response of power and frequency in the MG system. A comparison study on the control performance of the proposed VSG controller, the conventional VSG controller, and the conventional droop controller was presented. The sensitive analysis result showed that the proposed VSG controller could provide higher damping and lower overshoot than the conventional VSG controller. The proposed VSG controller could improve the overshoot of the transient response and the inertia response of the MG system. Although the overshoot of the transient response could be improved significantly by using the proposed VSG controller, the low frequency oscillation of power output and system frequency was slightly reduced. For practical application, the gain of the power derivative of the proposed controller should be chosen carefully to ensure the stability of the power converter. The proposed controller is suitable for an MG system that consists of both distributed generations and energy storage systems. It is also a potential solution for a wind farm where the power converter is used to integrate with the utility grid. 
Acknowledgments: This work was supported by the Korea Institute of Energy Technology Evaluation and Planning (KETEP) and the Ministry of Trade, Industry \& Energy (MOTIE) of the Republic of Korea (No. 20168530050030).

Author Contributions: Cao-Khang Nguyen conceived and designed the experiments; Thai-Thanh Nguyen and Hyeong-Jun Yoo performed the experiments and analyzed the results; Hak-Man Kim revised and analyzed the results; Cao-Khang Nguyen wrote the paper.

Conflicts of Interest: The authors declare no conflict of interest.

\section{Abbreviations}

$\begin{array}{llll}\text { DGs } & \text { Distributed generations } & Q_{\max } & \text { Maximum reactive power } \\ \text { MGs } & \text { Microgrids } & Q_{\text {min }} & \text { Minimum reactive power } \\ \text { RESs } & \text { Renewable energy sources } & J & \text { Virtual inertia } \\ \text { UPS } & \text { Uninterruptable power supply } & D & \text { Virtual damping factor } \\ \text { VSG } & \text { Virtual synchronous generator } & \theta & \text { Electrical angle } \\ \text { PSO } & \text { Partial swarm optimization } & \omega & \text { Angular frequency } \\ P-\omega & \text { Active power-frequency } & \omega_{N} & \text { Rated angular frequency } \\ P-V & \text { Active power-voltage } & k_{p} & \text { Droop coefficient } \\ k_{i c} & \text { Integral gain of current controller } & k_{q} & \text { Droop coefficient } \\ k_{i v} & \text { Proportional gain of current controller } & \frac{d P}{d t} & \text { Active power derivation } \\ P_{m} & \text { Mechanical power } & P & \text { Measured power of inverter } \\ m_{d} & \text { Modulating signal in d-frame } & k_{d} & \text { Derivative coefficient } \\ m_{q} & \text { Modulating signal in q-frame } & v_{0}^{*} & \text { Output voltage reference } \\ k_{p v} & \text { Proportional gain of voltage controller } & K & \text { Rating coefficient of proposed VSG control } \\ k_{p c} & \text { Integral gain of voltage controller } & Z_{v i r} & \text { Virtual output impedance } \\ V_{m a x} & \text { Maximum AC voltage } & L_{v i r} & \text { Virtual inductive component } \\ V_{\min } & \text { Minimum AC voltage } & i_{o} & \text { Output current } \\ \frac{d f}{d t} & \text { Frequency derivation } & v_{r e f} & \text { Output voltage reference using virtual impedance } \\ P^{*} & \text { Active power reference } & Q^{*} & \text { Reactive power reference } \\ V^{*} & \text { RMS voltage reference } & \omega^{*} & \text { Angular frequency reference }\end{array}$

\section{References}

1. Cecati, C.; Khalid, H.A.; Tinari, M.; Adinolfi, G.; Graditi, G. DC nanogrid for renewable sources with modular DC/DC LLC converter building block. IET Power Electron. 2016, 10, 536-544. [CrossRef]

2. Hatziargyriou, N.; Asano, H.; Iravani, R.; Marnay, C. Microgrids. IEEE Power Energy Mag. 2007, 5, 78-94. [CrossRef]

3. Rocabert, J.; Luna, A.; Blaabjerg, F.; Rodriguez, P. Control of power converters in AC microgrids. IEEE Trans. Power Electron. 2012, 27, 4734-4749. [CrossRef]

4. Pogaku, N.; Prodanovic, M.; Green, T.C. Modeling, analysis and testing of autonomous operation of an inverter-based microgrid. IEEE Trans. Power Electron. 2007, 22, 613-625. [CrossRef]

5. Guerrero, J.M.; De Vicuna, L.G.; Matas, J.; Castilla, M.; Miret, J. Output impedance design of parallel-connected UPS inverters with wireless load-sharing control. IEEE Trans. Ind. Electron. 2005, 52, 1126-1135. [CrossRef]

6. Guerrero, J.M.; Hang, L.; Uceda, J. Control of distributed uninterruptible power supply systems. IEEE Trans. Ind. Electron. 2008, 55, 2845-2859. [CrossRef]

7. Chandorkar, M.C.; Divan, D.M.; Adapa, R. Control of parallel connected inverters in standalone ac supply systems. IEEE Trans. Ind. Appl. 1993, 29, 136-143. [CrossRef]

8. Lopes, J.P.; Moreira, C.L.; Madureira, A.G. Defining control strategies for microgrids islanded operation. IEEE Trans. Power Syst. 2006, 21, 916-924. [CrossRef]

9. Olivares, D.E.; Mehrizi-Sani, A.; Etemadi, A.H.; Cañizares, C.A.; Iravani, R.; Kazerani, M.; Jimenez-Estevez, G.A. Trends in microgrid control. IEEE Trans. Smart Grid 2014, 5, 1905-1919. [CrossRef]

10. Li, Y.; Li, Y.W. Power management of inverter interfaced autonomous microgrid based on virtual frequency-voltage frame. IEEE Trans. Smart Grid 2011, 2, 30-40. [CrossRef] 
11. He, J.; Li, Y.W. Analysis, design, and implementation of virtual impedance for power electronics interfaced distributed generator. IEEE Trans. Ind. Appl. 2011, 47, 2525-2538. [CrossRef]

12. Vasquez, J.C.; Guerrero, J.M.; Savaghebi, M.; Eloy-Garcia, J.; Teodorescu, R. Modeling, analysis, and design of stationary-reference-frame droop-controlled parallel three-phase voltage source inverters. IEEE Trans. Ind. Electron. 2013, 60, 1271-1280. [CrossRef]

13. Mohamed, Y.A.R.I.; El-Saadany, E.F. Adaptive decentralized droop controller to preserve power sharing stability of paralleled inverters in distributed generation microgrids. IEEE Trans. Power Electron. 2008, 23, 2806-2816. [CrossRef]

14. Yu, K.; Ai, Q.; Wang, S.; Ni, J.; Lv, T. Analysis and optimization of droop controller for microgrid system based on small-signal dynamic model. IEEE Trans. Smart Grid 2016, 7, 695-705. [CrossRef]

15. Han, H.; Hou, X.; Yang, J.; Wu, J.; Su, M.; Guerrero, J.M. Review of power sharing control strategies for islanding operation of AC microgrids. IEEE Trans. Smart Grid 2016, 7, 200-215. [CrossRef]

16. Feng, X. Dynamic balancing for low inertia power systems. In Proceedings of the 2013 IEEE Power and Energy Society General Meeting (PES), Vancouver, BC, Canada, 21-25 July 2013; pp. 1-5.

17. Tang, X.; Deng, W.; Qi, Z. Investigation of the dynamic stability of microgrid. IEEE Trans. Power Syst. 2014, 29, 698-706. [CrossRef]

18. Doherty, R.; Mullane, A.; Nolan, G.; Burke, D.J.; Bryson, A.; O'Malley, M. An assessment of the impact of wind generation on system frequency control. IEEE Trans. Power Syst. 2010, 25, 452-460. [CrossRef]

19. Delille, G.; Francois, B.; Malarange, G. Dynamic frequency control support by energy storage to reduce the impact of wind and solar generation on isolated power system's inertia. IEEE Trans. Sustain. Energy 2012, 3, 931-939. [CrossRef]

20. Zhong, Q.C.; Weiss, G. Synchronverters: Inverters that mimic synchronous generation. IEEE Trans. Ind. Electron. 2011, 58, 1259-1267. [CrossRef]

21. Zhong, Q.C.; Nguyen, P.L.; Ma, Z.; Sheng, W. Self-synchronized synchronverters: Inverters without a dedicated synchronization unit. IEEE Trans. Power Electron. 2014, 29, 617-630. [CrossRef]

22. Liu, J.; Miura, Y.; Ise, T. Comparison of dynamic characteristics between virtual synchronous generator and droop control in inverter-based distributed generation. IEEE Trans. Power Electron. 2016, 31, 3600-3611. [CrossRef]

23. Zhao, H.; Yang, Q.; Zeng, H. Multi-loop virtual synchronous generator control of inverter-based DGs under microgrid dynamics. IET Gener. Transm. Distrib. 2017, 11, 795-803. [CrossRef]

24. Hirase, Y.; Sugimoto, K.; Sakimoto, K.; Ise, T. Analysis of resonance in microgrids and effects of system frequency stabilization using a virtual synchronous generator. IEEE J. Emerg. Sel. Top. Power Electron. 2016, 4, 1287-1298. [CrossRef]

25. Van Wesenbeeck, M.P.N.; De Haan, S.W.H.; Varela, P.; Visscher, K. Grid tied converter with virtual kinetic storage. In Proceedings of the 2009 IEEE Bucharest PowerTech, Bucharest, Romania, 28 June-2 July 2009; pp. 1-7.

26. Soni, N.; Doolla, S.; Chandorkar, M.C. Improvement of transient response in microgrids using virtual inertia. IEEE Trans. Power Deliv. 2013, 28, 1830-1838. [CrossRef]

27. Wu, H.; Ruan, X.; Yang, D.; Chen, X.; Zhao, W.; Lv, Z.; Zhong, Q.C. Small-signal modeling and parameters design for virtual synchronous generators. IEEE Trans. Ind. Electron. 2016, 63, 4292-4303. [CrossRef]

28. D'Arco, S.; Suul, J.A.; Fosso, O.B. A Virtual Synchronous Machine implementation for distributed control of power converters in SmartGrids. Electr. Power Syst. Res. 2015, 122, 180-197. [CrossRef]

29. Palizban, O.; Kauhaniemi, K.; Guerrero, J.M. Microgrids in active network management-Part I: Hierarchical control, energy storage, virtual power plants, and market participation. Renew. Sustain. Energy Rev. 2104, 36, 428-439. [CrossRef]

(C) 2017 by the authors. Licensee MDPI, Basel, Switzerland. This article is an open access article distributed under the terms and conditions of the Creative Commons Attribution (CC BY) license (http:// creativecommons.org/licenses/by/4.0/). 